\title{
Correction to: Printed flexible bifunctional electrochemical urea-pH sensor based on multiwalled carbon nanotube/polyaniline electronic ink
}

\author{
Qiwen Bao ${ }^{1}$. Zhengchun Yang ${ }^{1}$ - Yanfei Song ${ }^{1} \cdot$ Meiying Fan ${ }^{1} \cdot$ Peng Pan ${ }^{1} \cdot$ Jun Liu ${ }^{1} \cdot$ Zhenyu Liao $^{2,3} \cdot$ Jun Wei $^{1,4}$
}

Published online: 22 February 2019

(c) Springer Science+Business Media, LLC, part of Springer Nature 2019

\section{Correction to:}

Journal of Materials Science: Materials in Electronics https://doi.org/10.1007/s10854-018-0447-5

In the original version of this article, Fig. 7a, b and c was

unfortunately displayed incorrectly.
The correct results of Fig. 7a, b and $\mathrm{c}$ is showed as follows. (a)

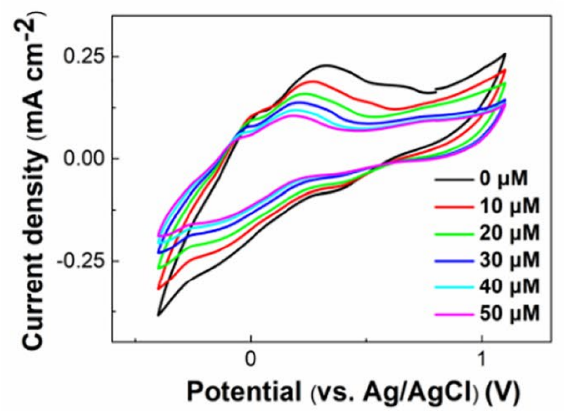

(b)

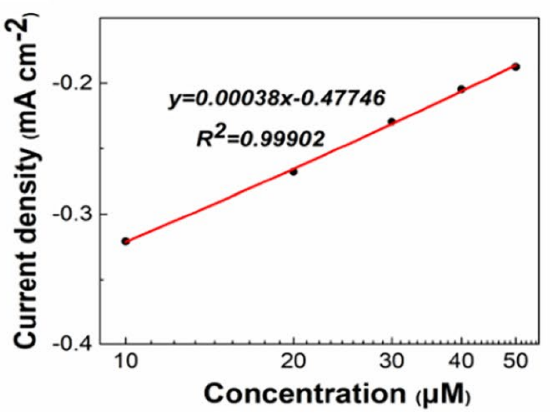

(c)

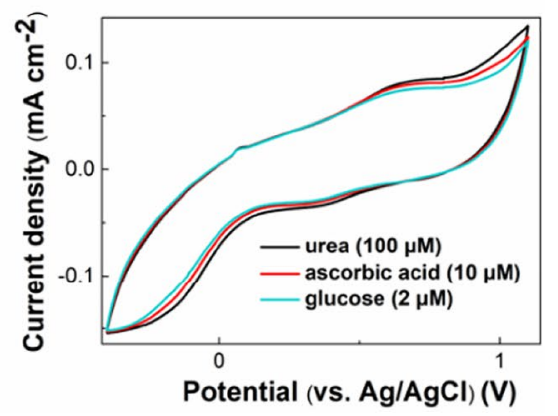

Fig. 7 a $I-V$ responses of MWCNT/PANi-composite-modified SPCE at urea concentration range of $10-50 \mu \mathrm{M}$ and scan rate of $50 \mathrm{mV} \mathrm{s}{ }^{-1}$. b Corresponding calibration curve. $\mathrm{c} I-V$

The original article can be found online at https://doi.org/10.1007/ s10854-018-0447-5.

Peng Pan

panpeny@163.com

$\triangle$ Jun Liu

cloudlj@163.com

$\triangle$ Zhenyu Liao

liaozy08@163.com

1 School of Electrical and Electronic Engineering, Tianjin Key Laboratory of Film Electronic \& Communication Devices, Advanced Materials and Printed Electronics Center, Tianjin University of Technology, Tianjin 300384, China
Publisher's Note Springer Nature remains neutral with regard to jurisdictional claims in published maps and institutional affiliations. 